\title{
Fluoroscopy-Guided Axillary Vein Puncture, a Reliable Method to Prevent Acute Complications Associated With Pacemaker, Defibrillator, and Cardiac Resynchronization Therapy Leads Insertion
}

E.M. Malitha S. Hettiarachchi, Camelia Arsene*, Salah Fares, Adriss Faraj, Erik Saulitis, Salvatory Losito and Mukarram Siddiqui

Department of Medicine, Sinai-Grace Hospital / Detroit Medical Center, MI, USA

\begin{abstract}
Introduction: The subclavian venous approach is a widely used method for venous access in device implantation and is associated with pneumothorax as a short term complication and lead fracture as a long term complication. The axillary vein approach is an alternate method for venous access, and this study evaluates the successfulness and immediate complications of fluoroscopy-guided axillary vein puncture compared to other venous approach methods.

Methods: This is a retrospective observational study on all patients who underwent pacemaker, defibrillator implant or lead change over 23 months. The fluoroscopy-guided modified Seldinger technique was used for axillary vein puncture and if failed, venography was performed.

Results: Out of 261 device implants or lead changes, 210 patients underwent fluoroscopy-guided axillary vein puncture. The mean age of the patients was $65.43 \pm 15.7$ years; $96.1 \%$ were African American; $57.6 \%$ were males. In $194(92.3 \%)$ patients left or right axillary vein approaches were successful by either fluoroscopy or venography guidance. When anatomical abnormalities were excluded the success rate for axillary vein puncture was $97 \%$ and for fluoroscopy-guided axillary vein puncture was $94.5 \%$. Multiple leads were placed without any resistance and none of the patients had pneumothorax, hemothorax or hematoma as immediate complications.

Conclusion: Based on this first study conducted in a relatively large consecutive United Sates patient population, we report that fluoroscopy-guided axillary vein puncture using the first rib as a landmark, is a safe and effective method for device implantation with single or multiple leads, without patients getting exposed to intravenous contrasts.
\end{abstract}

Keywords: Fluoroscopy guided; Axillary vein; Pacemaker; Defibrillator implant; Immediate complications

\section{Introduction}

Infraclavicular subclavian approach, cephalic vein cut down, and axillary vein puncture are accepted methods for implanting endocardial pacemaker and transvenous defibrillator leads. Even though the subclavian approach is a widely used method for lead placement in cardiac pacing, different acute complications like for example a 1-3\% incidence of pneumothorax or hemothorax have been noted [1-4]. Furthermore, lead fracture due to the entrapment of the lead by the costoclavicular ligament and/or the subclavius muscle, has been presented as subclavian crush and is a major concern [5,6]. As an alternative method, cephalic cut down has been shown to be associated with a lower incidence of lead fracture but the cephalic venous approach requires skills in surgical cut-down technique and the vessel's smaller diameter makes insertion of multiple large diameter leads more technically demanding [7]. As a solution to problems associated with cephalic vein cut down, the axillary vein puncture has been tried. Experience with axillary vein approach is mainly clinical and limited, and immediate and long term complications over other methods are not well established in observational studies [8,9].

We present our single center experience in fluoroscopy-guided axillary vein puncture using the modified Seldinger technique. This study was approved by the Institutional Review Board.

\section{Methods}

\section{Study methods}

This is a retrospective observational study done on all patients who underwent a pacemaker, a defibrillator device implant or lead change for a period of 23 months in our institution. Patient information was gathered by chart review, specifically from operative/procedure notes.

\section{Axillary vein cannulation}

Clinical anatomy: The axillary vein is a large vein that is a continuation of the bacilic vein (Figure 1). It starts at the lower border of the teres major tendon and terminates immediately beneath the clavicle at the outer border of the first rib, where it becomes the subclavian vein. It is anterior and medial to the axillary artery and brachial plexus and partially overlaps. At the level of the coracoid process, the axillary vein receives the lateral cephalic vein [10].

Procedure: We access the axillary vein under fluoroscopy. An incision is made just medial to the coracoid process in the middle of the deltopectoral groove and carried inferomedially in a direction perpendicular to the deltopectoral groove. The incision is carried down to the surface of the pectoralis major muscle. The image intensifier is

*Corresponding author: Camelia Arsene, Department of Medicine, SinaiGrace Hospital/Detroit Medical Center, 6071 West Outer Drive, Detroit Medical Center, MI 48235, USA, Tel: 313-966-9014; Fax: 313-966-1738, E-mail: carsene@dmc.org

Received November 28, 2013; Accepted December 30, 2013; Published January 06, 2014

Citation: Hettiarachchi EMMS, Arsene C, Fares S, Faraj A, Saulitis E, et al (2014) Fluoroscopy-Guided Axillary Vein Puncture, a Reliable Method to Prevent Acute Complications Associated With Pacemaker, Defibrillator, and Cardiac Resynchronization Therapy Leads Insertion. J Cardiovasc Dis Diagn 2: 136. doi:10.4172/2329-9517.1000136

Copyright: (C) 2014 Hettiarachchi EMMS, et al. This is an open-access article distributed under the terms of the Creative Commons Attribution License, which permits unrestricted use, distribution, and reproduction in any medium, provided the original author and source are credited. 
Citation: Hettiarachchi EMMS, Arsene C, Fares S, Faraj A, Saulitis E, et al. (2014) Fluoroscopy-Guided Axillary Vein Puncture, a Reliable Method to Prevent Acute Complications Associated With Pacemaker, Defibrillator, and Cardiac Resynchronization Therapy Leads Insertion. J Cardiovasc Dis Diagn 2: 136. doi:10.4172/2329-9517.1000136

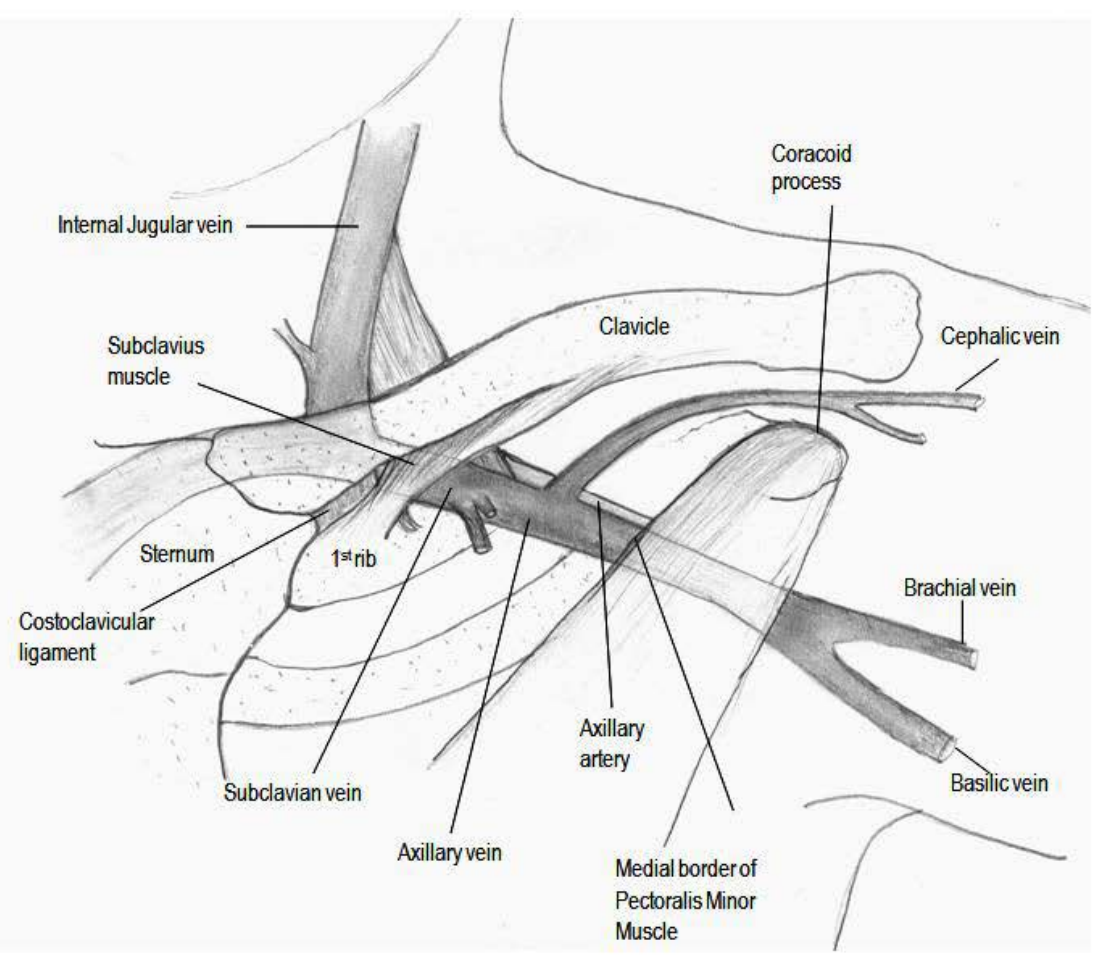

Figure 1: Anatomy of the axillary vein and superficial landmarks.

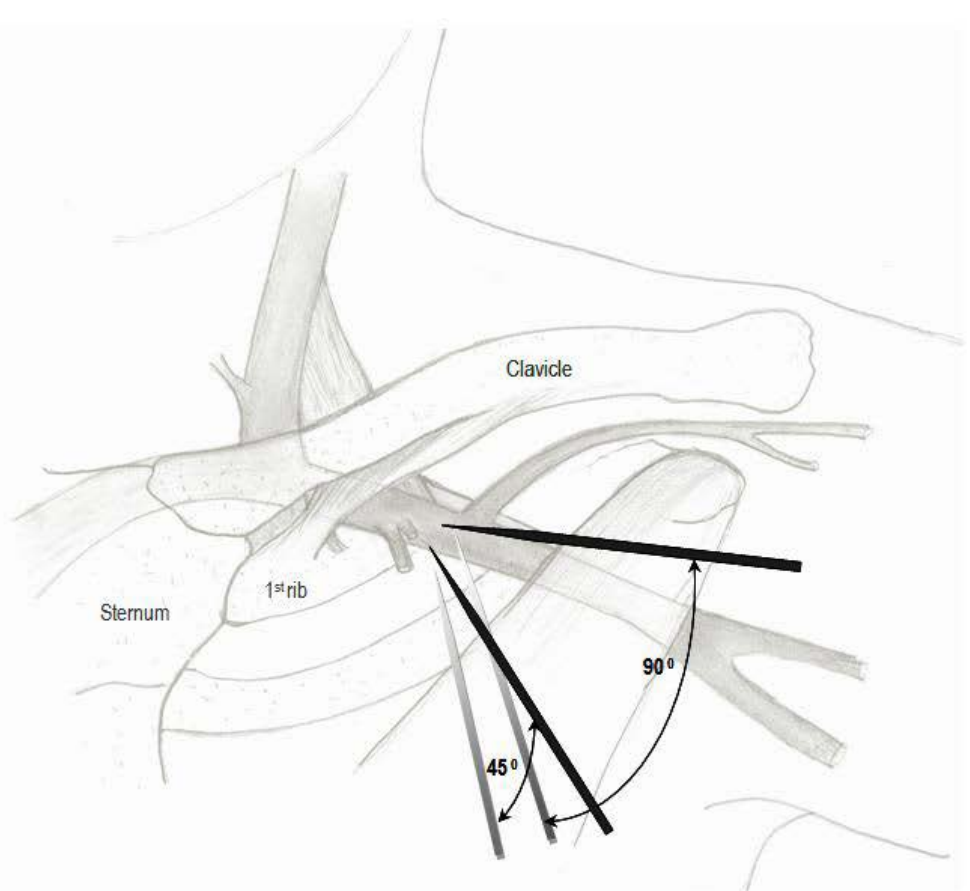

Figure 2: The angle of the needle in relationship to the first rib. Needle should be angled to 60 to 90 degrees as shallow angle runs the risk of entering the intercostal space, causing pneumothorax.

pulled over to the incision and the first rib is identified. An 18 gauge percutaneous needle and syringe is placed on pectoralis major muscle in the superior aspect of the incision. Using fluoroscopy the needle tip is placed in the middle of the first rib (Figure 2 and 3 ). The angle of the needle and syringe is advanced from $60^{\circ}$ to $90^{\circ}$ as needle is advanced through the pectoral muscle. Needle advancement is continued until the first rib is struck. Once the first rib is touched, the needle and syringe are slowly withdrawn under suction until the vein is entered. If the first pass is unsuccessful the needle and syringe are moved either medially or laterally along the first rib, and the maneuver repeated until 
Citation: Hettiarachchi EMMS, Arsene C, Fares S, Faraj A, Saulitis E, et al. (2014) Fluoroscopy-Guided Axillary Vein Puncture, a Reliable Method to Prevent Acute Complications Associated With Pacemaker, Defibrillator, and Cardiac Resynchronization Therapy Leads Insertion. $J$ Cardiovasc Dis Diagn 2: 136. doi:10.4172/2329-9517.1000136

Page 3 of 5

\begin{tabular}{|c|c|}
\hline Venous puncture site & Number of patients \\
\hline Total left axillary attempted & 210 \\
\hline Left axillary successful & 190 \\
\hline Left axillary failed then, & 20 \\
right axillary & 4 \\
subclavian & 9 \\
\hline Cephalic cut down & 7 \\
\hline Primarily other site & 51 \\
common femoral & 1 \\
subclavian-- left & 17 \\
subclavian --right & 4 \\
cephalic cut down & 29 \\
\hline Total device/lead change & 261 \\
\hline
\end{tabular}

Table 1: Type of venous access obtained for device implant or lead change during the study period.

\begin{tabular}{|c|c|c|c|c|c|}
\hline $\begin{array}{c}\text { Procedure/ } \\
\text { Fluoroscopy time } \\
\text { (seconds) }\end{array}$ & Mean & Median & $\begin{array}{c}\text { Standard } \\
\text { deviation }\end{array}$ & Minimum & Maximum \\
\hline $\begin{array}{c}\text { 1-single chamber } \\
\text { pacemaker }\end{array}$ & 8.0 & 8.7 & 3.0 & 4.3 & 10.8 \\
\hline $\begin{array}{c}\text { 2-dual chamber } \\
\text { pacemaker }\end{array}$ & 6.2 & 5.8 & 3.1 & 1.1 & 15.9 \\
\hline 3-single chamber ICD & 6.7 & 4.6 & 7.4 & 0.8 & 35.1 \\
\hline 4-dual chamber ICD & 9.1 & 8.1 & 6.1 & 2.2 & 32.0 \\
\hline 5-bivent CRTD & 18.4 & 15.6 & 11.7 & 4.4 & 58.9 \\
\hline 6-lead replace & 9.4 & 6.9 & 7.2 & 2.1 & 30.0 \\
\hline
\end{tabular}

Table 2: Fluoroscopy time for different procedures.

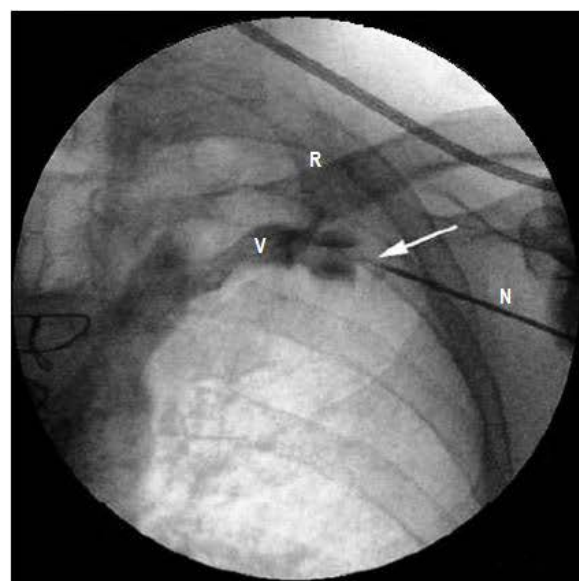

Figure 3: Flouroscopic view of the axillary vein approach $\mathrm{R}$-first rib, N-needle, $\mathrm{V}$-axillary vein draining into subclavain vein.

the vein is entered. Once the vein is entered the guide wire is passed and the sheath applied per standard technique $[10,11]$.

Multiple accesses are obtained if the patient requires dual chamber permanent pace maker/ defibrillator or biventricular implantable cardioverter defibrillator.

The method to fix the lead at the venous access site is the one described by Peter Belott [12].

\section{Results}

Two hundred and sixty-one patients underwent device implant or lead change during the study period (Table 1). In 210 patients fluoroscopy-guided left axillary vein approach was performed, and in 51 patients the subclavian or cephalic access was utilized.

The median fluoroscopy time was 6.8 seconds with a range of 0.1 to 58.9 seconds. Table 2 presents the fluoroscopy time data for different procedures.

The mean age of the patients who underwent axillary vein approach was $65.43 \pm 15.78$ years. The majority of them, $96.1 \%$, were African American and $57.6 \%$ were males.

Out of 210 patients who had axillary vein approach attempted, in 194 patients (92.3\%) left or right axillary vein approaches were successful by either fluoroscopic or venography guidance (Table 1 and Figure 4). In $16(7.6 \%)$ patients axillary vein puncture was not successful and alternative sites were required.

The identified reasons for unsuccessful cannulation were anatomical variations/ abnormalities including persistence of left superior vena cava (then venous access was obtained in right axillary vein), venous obstruction, tortuosity of the axillary vein, and clavicular and rib abnormalities. Venous stenosis was also seen in two patients: a hemodialysis patient and an intravenous drug user. After the anatomical abnormalities were excluded, the success rate for axillary vein puncture (either fluoroscopy or venography guidance) was $97 \%$ and the success rate for fluoroscopy-guided axillary vein puncture was $94.5 \%$ (Table 3 ).

Once the venous access was obtained, pacemaker leads or defibrillator leads were successfully placed via the axillary vein regardless of the number of leads, ranging from 1 to 3. Difficulty in placing introducer sheath or lead was not seen in any patients. The characteristics of the devices and the number of leads successfully placed are shown in Table 4. A total of 325 successful axillary vein punctures were performed. Lead removal and replacement were also done successfully in patients who had a preexisting device.

The patients were watched for immediate complications clinically and radiographycally: postero-anterior and lateral chests X-ray were performed and none of the patients had pneumothorax or hemothorax as immediate complications.

\section{Discussion}

Other operators have published different techniques to mark the position of the axillary vein, and for example the anterior side of the second rib was used as the guiding site for puncture site and direction (9). Our study used the first rib as landmark, not the second rib, and therefore this method prevented excessive bleeding at the puncture site and allowed for better and easier lead fixation. Although this could be considered as a technique sometimes used in the clinical practice, we have done a thorough literature review, and we found only one retrospective chart review published study conducted in a smaller patient population in Israel, that used the most lateral edge of the first rib as a fluoroscopic landmark [13].

Venous access is one of the most important steps in device implantation and the subclavian approach is a widely used method. The subclavian vein access is associated with short and long term complications: $1-3 \%$ of the incidence of pneumothorax or hemothorax as acute complications and subclavian crush phenomenon leading to lead fracture as a long term complication [5,6]. As shown in our study, axillary vein puncture is not associated with immediate complications [2-4].

Out of the small number of published data on axillary vein puncture most are non United States smaller scale studies that compare various methods, namely, the contrast venography-guided, the Dopplerguided, and the ultrasound-guided puncture methods except for a few studies done in Israel, Japan and India with fluoroscopy-guided 
Citation: Hettiarachchi EMMS, Arsene C, Fares S, Faraj A, Saulitis E, et al. (2014) Fluoroscopy-Guided Axillary Vein Puncture, a Reliable Method to Prevent Acute Complications Associated With Pacemaker, Defibrillator, and Cardiac Resynchronization Therapy Leads Insertion. $J$ Cardiovasc Dis Diagn 2: 136. doi:10.4172/2329-9517.1000136

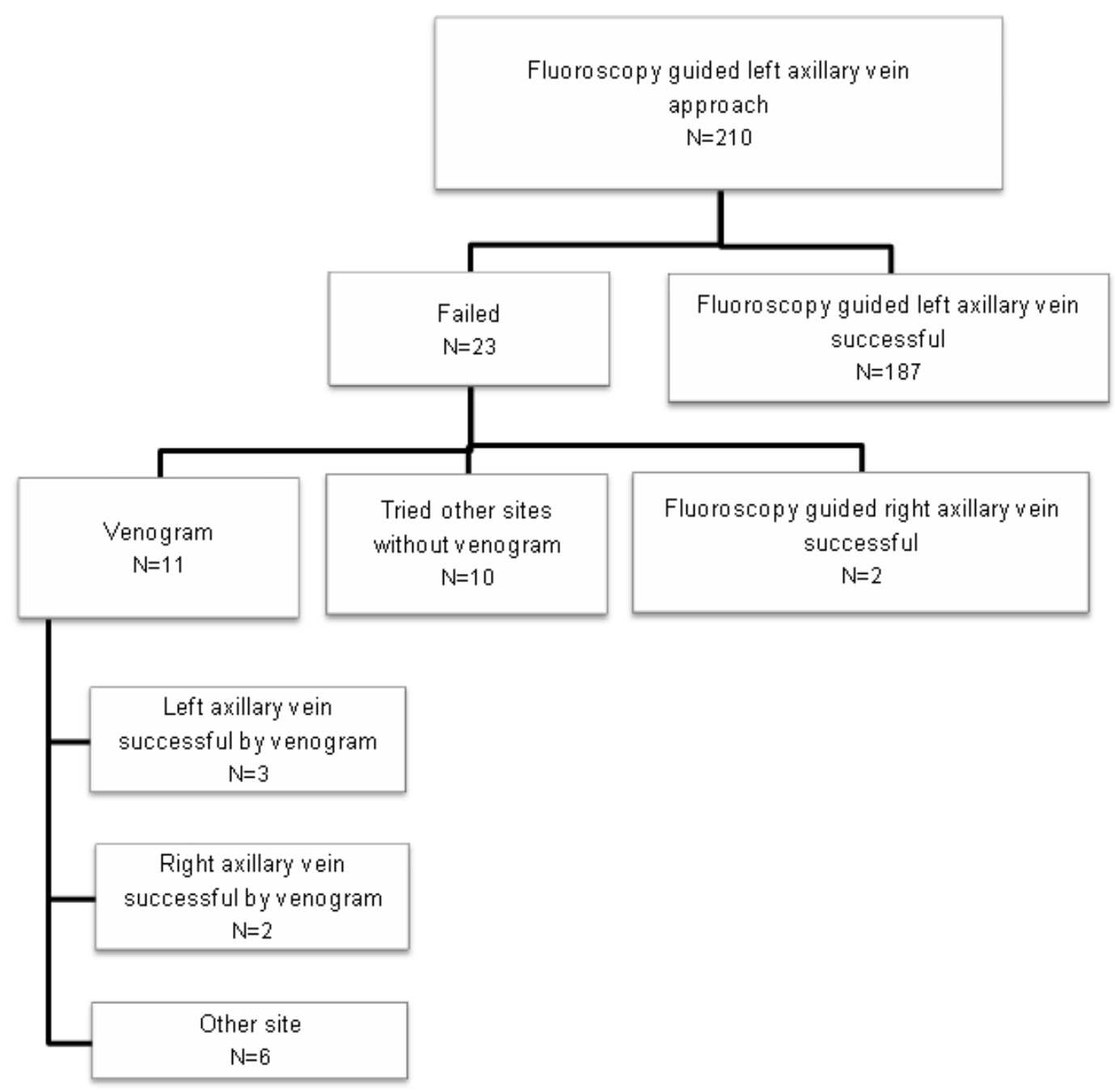

Figure 4: Flouroscopy-guided axillary vein approach.

\begin{tabular}{|c|c|}
\hline \multicolumn{1}{|c|}{ Success rate } & Patients \\
\cline { 2 - 3 } Axillary vein puncture successful (by fluoroscopy or venogram) & $194 / 210$ \\
\hline Axillary vein puncture not successful & $16 / 210$ \\
\hline Failures due to anatomical variations & $10 / 16$ \\
\hline Axillary vein puncture successful - after excluding anatomical variations & $194 / 200$ \\
\hline Axillary vein puncture successful with fluoroscopy & $7.6 \%$ \\
\hline Axillary vein puncture successful with fluoroscopy - after excluding anatomical variations & $97 \%$ \\
\hline
\end{tabular}

Table 3: Success rate of right or left axillary vein puncture.

approach [9,11,13-15]. This study is a North-American experience with fluoroscopy-guided axillary vein puncture using the first rib as a landmark; it is done in a relatively large African-American population, and discusses the immediate complications of the procedure.

Our study shows that fluoroscopy-guided axillary vein puncture is a safe method with limited immediate complications. There was an overall $97 \%$ success in axillary vein puncture (either fluoroscopy-guided or venography-guided) after excluding failures due to anatomical abnormalities. Fluoroscopy-guided axillary vein puncture alone also had a success rate of $94.5 \%$ after excluding failures due to anatomical abnormalities.
The main advantages of fluoroscopy-guided approach are that patients are not exposed to the hazards of intravenous contrasts as in venography-guided approach, and the reduced incidence of pneumothorax or hemothorax. While some literature mentions the difficulty in measuring the depth of the vessel with fluoroscopy guidance we did not recognize it as a major barrier [14]. Most importantly, multiple access could be obtained for multiple leads to be inserted without any failure. We did not experience any immediate complications such as pneumothorax or hemothorax, and this could be correlated with the advanced experience of the principal investigator. According to the published literature, leads placed with axillary vein 
Citation: Hettiarachchi EMMS, Arsene C, Fares S, Faraj A, Saulitis E, et al. (2014) Fluoroscopy-Guided Axillary Vein Puncture, a Reliable Method to Prevent Acute Complications Associated With Pacemaker, Defibrillator, and Cardiac Resynchronization Therapy Leads Insertion. $J$ Cardiovasc Dis Diagn 2: 136. doi:10.4172/2329-9517.1000136

Page 5 of 5

\begin{tabular}{|c|c|c|c|}
\hline \multirow{2}{*}{ Device type } & \multicolumn{2}{|c|}{ Patients } & \multirow{2}{*}{$\begin{array}{l}\text { Number of } \\
\text { punctures at } \\
\text { axillary vein }\end{array}$} \\
\hline & Number & Percentage & \\
\hline 1-single chamber pacemaker & 10 & $5.3 \%$ & 10 \\
\hline 2-dual chamber pacemaker & 42 & $22.2 \%$ & 84 \\
\hline 3-single chamber ICD & 48 & $25.4 \%$ & 48 \\
\hline 4-dual chamber ICD & 22 & $11.6 \%$ & 44 \\
\hline 5-bivent CRTD & 36 & $19 \%$ & 108 \\
\hline 6- ICD upgrade to bivent CRTD & 12 & $6.3 \%$ & 12 \\
\hline 7-lead replace & 19 & $10 \%$ & 19 \\
\hline Total & 189 & & 325 \\
\hline \multicolumn{4}{|l|}{ Number of leads inserted } \\
\hline 1 & 74 & $39.2 \%$ & \\
\hline 2 & 67 & $35.4 \%$ & \\
\hline 3 & 48 & $25.4 \%$ & \\
\hline \multicolumn{4}{|l|}{ Pre-exciting leads } \\
\hline present & 32 & $16.9 \%$ & \\
\hline absent & 157 & $83.1 \%$ & \\
\hline
\end{tabular}

Table 4: Characteristics of the devices /leads placed successfully with fluoroscopyguided left or right axillary vein approach.

approach have minimum risk for lead fracture [16]. To identify the long term complications including lead fracture, we will be following these patients for 12 to 24 months prospectively.

The main limitations of this study are the fact that this is a retrospective observational study, and also there is no direct comparison between fluoroscopy-guided axillary vein puncture and the traditional methods of vascular access, like venography-guided axillary vein puncture, cephalic vein cut down or subclavian vein puncture.

\section{Conclusion}

We report that fluoroscopy-guided axillary vein puncture using the modified Seldinger technique is a safe and effective method for the implantation of pacemaker of defibrillator device with single or multiple leads, and it has limited immediate complications.

\section{References}

1. Byrd CL (1992) Safe introducer technique for pacemaker lead implantation. Pacing Clin Electrophysiol 15: 262-267.

2. Aggarwal RK, Connelly DT, Ray SG, Ball J, Charles RG (1995) Early complications of permanent pacemaker implantation: no difference between dual and single chamber systems. Br Heart J 73: 571-575.

3. Chauhan A, Grace AA, Newell SA, Stone DL, Shapiro LM, et al. (1994) Early complications after dual chamber versus single chamber pacemaker implantation. Pacing Clin Electrophysiol 17: 2012-2015

4. Parsonnet V, Bernstein AD, Lindsay B (1989) Pacemaker-implantation complication rates: an analysis of some contributing factors. J Am Coll Cardiol 13: $917-921$.

5. Magney JE, Flynn DM, Parsons JA, Staplin DH, Chin-Purcell MV, et al. (1993) Anatomical mechanisms explaining damage to pacemaker leads, defibrillator leads, and failure of central venous catheters adjacent to the sternoclavicular joint. Pacing Clin Electrophysiol 16: 445-457.

6. Roelke M, O'Nunain SS, Osswald S, Garan H, Harthorne JW, et al. (1995) Subclavian crush syndrome complicating transvenous cardioverter defibrillator systems. Pacing Clin Electrophysiol 18: 973-979.

7. Gallik DM, Ben-Zur UM, Gross JN, Furman S (1996) Lead fracture in cephalic versus subclavian approach with transvenous implantable cardioverter defibrillator systems. Pacing Clin Electrophysiol 19: 1089-1094.

8. Hsu JC, Friday J, Lee BK, Azadani PN, Lee RJ, et al. (2011) Predictors of axillary vein location for vascular access during pacemaker and defibrillator lead implantation. Pacing Clin Electrophysiol 34: 1585-1592.

9. Sharma G, Senguttuvan NB, Thachil A, Leong D, Naik N, et al. (2012) A comparison of lead placement through the subclavian vein technique with fluoroscopy-guided axillary vein technique for permanent pacemaker insertion. Can J Cardiol 28: 542-546.

10. Belott $P$ (2006) How to access the axillary vein. Heart Rhythm 3: 366-369.

11. Nickalls RW (1987) A new percutaneous infraclavicular approach to the axillary vein. Anaesthesia 42: 151-154.

12. Belott P (2001) Implantation techniques for single- and dual-chambe pacemakers. In Singer I, Eds, Interventional Electrophysiology $\left(2^{\text {nd }} E d n\right)$, Lippincott Williams \& Wilkins, USA.

13. Antonelli D, Feldman A, Freedberg NA, Turgeman $Y$ (2013) Axillary vein puncture without contrast venography for pacemaker and defibrillator leads implantation. Pacing Clin Electrophysiol 36: 1107-1110.

14. Kawakami T, Ichinose H (2004) Double target method (double marker-guided extrathoracic introducer insertion). Pacing Clin Electrophysiol 27: 818-820.

15. Yadav R, Chandra S, Naik N (2006) Modified fluoroscopy-guided axillary vein puncture during pacemaker implantation: acute and mid-term results.

16. Ramza BM, Rosenthal L, Hui R, Nsah E, Savader S, et al. (1997) Safety and effectiveness of placement of pacemaker and defibrillator leads in the axillary vein guided by contrast venography. Am J Cardiol 80: 892-896. 